\title{
PPD and hsp65 induced monoarthritis initiates spontaneous recurrent flares in Lewis rats
}

\author{
Silvia Ragno, Christopher J Morris, Adam Coumbe, Paul I Mapp, M Joseph Colston, \\ David R Blake, Vivienne R Winrow
}

\begin{abstract}
Objectives-To investigate the time course of a monoarthritis induced with the purified protein derivative of tuberculin (PPD) or a recombinant $65 \mathrm{kDa}$ heat shock protein (rhsp65) in two different strains of sensitised rats.

Methods-Wistar and Lewis rats, sensitised with heat killed Mycobacterium tuberculosis in oil, were challenged intraarticularly with PPD or rhsp65 and monitored for six weeks. Inflammation was assessed by joint swelling, histology, and radiographic studies.

Results-Sensitised Lewis rats injected with PPD or rhsp65 showed a chronic response with recurrent spontaneous flares, while Wistar rats showed one inflammatory episode.

Conclusions-The Wistar strain response to PPD resembles a transient reactive arthritis, while the response of the Lewis strain mimics the relapsing nature of rheumatoid synovitis, providing an interesting model to determine dominant immunopathogenic mechanisms.
\end{abstract}

(Ann Rheum Dis 1995; 54: 59-65)

Rheumatoid arthritis (RA) is characterised by a progressive erosive synovitis with superimposed acute inflammatory episodes (flares). The disease course varies between individuals, probably as a result of multifactorial genetic or environmental conditions, or both. ${ }^{1}$ The initial antigenic trigger or secondary antigenic factors responsible for the flares have not been defined.

McCulloch et $a l^{2}$ have reviewed the clinical similarities between RA and the mycobacterioses, highlighting their striking resemblance, particularly in terms of autoimmune features, and suggested that slow growing organisms may be accountable for the as yet undefined synovial antigen. When growing in the hostile environment of the mammalian host Mycobacterium tuberculosis has many characteristics of a 'stationary phase' bacterium. Stationary phase organisms can express $30-50$ new genes, particularly heat shock proteins (hsp) and superantigens, some of these genes being transcribed only under stressful in vivo circumstances. ${ }^{2}$ Moreover a 'reactive arthritis' $(\operatorname{ReA})$ can accompany certain slow bacterial infections, in a manner similar in some ways to that seen in patients transiently infected in the gut or genitourinary tract by Yersinia, Chlamydia, Shigella, Salmonella, etc. It is characteristic of $\operatorname{ReA}$ that the causative organism cannot be isolated from the joint, but the joint contains both antigens derived from the organism and $\mathrm{T}$ cells responding to those antigens. $^{3}{ }^{4}$

Heat shock proteins have been implicated in experimental models of arthritis ${ }^{5-10}$ and hsp-reactive $T$ cells have been demonstrated in the joints of patients with $\mathrm{RA}^{11}$ and ReA. ${ }^{12}$ Furthermore, enhanced local expression of $65 \mathrm{kDa}$ heat shock protein (hsp65) occurs in the inflamed synovium of patients with $\mathrm{RA}^{1314}$ and arthritic rats. ${ }^{14}$ In man, priming of the immune system to hsp is a common phenomenon occurring early in life via BCG vaccination and the trivalent vaccine against tetanus, diphtheria and pertussis. Since hsp are immunodominant and evolutionary conserved antigens, the question arises as to whether such a priming could contribute to the induction of autoimmune disorders: ${ }^{15} 16$ it has been suggested that autoimmune diseases may be initiated or perpetuated by $\mathrm{T}$ cells recognising cross reactive hsp epitopes. ${ }^{17}$

Previously, we showed that intra-articular injection of either rhsp65 or the purified protein derivative of $M$. tuberculosis (M.tb) (PPD), which contains hsp65, ${ }^{18}$ could induce an acute monoarthritis in M.tb immunised but not in non-immunised Wistar rats. Swelling subsided within seven days, but hsp antibody titres were still increasing, indicating a still active immune response. ${ }^{19}$ As the variety of established animal models of RA, including those induced by Freund's complete adjuvant, streptococcal cell walls and type II collagen ${ }^{20}{ }^{21}$ do not accurately mimic the persistent reaction seen in the human condition, we reasoned that the conserved and cross reactive nature of hsp might itself contribute to the development of chronic disease in susceptible individuals.

Wistar rats are an outbred strain. However, Lewis rats, an inbred strain, show an increased susceptibility to develop arthritis because of both their genetic predisposition and a neuroimmune disorder also reported in patients with RA. ${ }^{22}{ }^{23}$ Thus, after priming, we compared the response of these two strains of rats to a single intra-articular injection of PPD or rhsp65. 


\section{Materials and methods}

ANIMALS

Female Wistar and Lewis rats were obtained from Charles River (Margate, Kent, UK) and Harlan Orlac (Bicester, Oxon, UK) respectively. The animals weighed $150-170 \mathrm{~g}$ at the start of the experiment. Young female rats were chosen because they are more susceptible to induction of arthritis.

\section{LONG TERM TUBERCULIN MONOARTHRITIS}

MODEL

Heat-killed human strains C, DT and PN of Mycobacterium tuberculosis (Central Veterinary Laboratory, Weybridge, UK) were finely ground in a pestle and mortar and suspended in light paraffin oil to a final concentration of $10 \mathrm{mg} / \mathrm{ml}$. Female Wistar and Lewis rats were inoculated intradermally in the nape of the neck with a total of $100 \mu \mathrm{l}$ of the suspension. After seven days, groups of rats were challenged intra-articularly (i-a) in the right knee with $50 \mu \mathrm{l}(1 \mathrm{mg} / \mathrm{ml})$ of PPD (Purified Protein Derivative of $M . t b$, strain 289; Central Veterinary Laboratory) or with the vehicle (phosphate buffered saline (PBS)) as control. A second control group of sensitised animals received no i-a injection. Knee swelling, used as an indicator of joint inflammation, was assessed as the difference in widths measured with a digital caliper (RS Components, Corby, Northamptonshire, UK), of the injected (right) and uninjected (left) joints. Measurements were made at several times after injection as previously described. ${ }^{19}$ After initial swelling subsided, the rats were monitored daily for 42 days after i-a injection and, if further knee swelling was evident, measurements were recorded. A sufficient number of rats were inoculated to provide five to six animals for sacrifice at each time of measurement (days 3, 14,28 , and 42). Joints were transferred to formol saline for radiographic and histopathological evaluation.

A second group of 10 Lewis rats were sensitised with M.tb and subsequently challenged in the right knee joint with $50 \mu \mathrm{l}$ of $1 \mathrm{mg} / \mathrm{ml}$ recombinant mycobacterial $65 \mathrm{kDa}$ protein (rhsp65) from Mycobacterium leprae. $^{24}$

\section{HISTOPATHOLOGY}

The right and left knees of animals used in the radiographic studies were subsequently decalcified $(5 \%$ formic acid in formol saline), embedded in paraffin, and sectioned longitudinally. Joint sections $(7 \mu \mathrm{m})$ were prepared and stained with haematoxylin and eosin. Blinded assessment of the sections was made by three operators on the basis of (a) presence of fibrin-like material deposited in the joint cavity, (b) an inflammatory cell infiltrate in the synovium, (c) destruction of articular cartilage by pannus formation, and (d) periostitis. Tissues were graded from 0 to 3 according to the presence and severity of the above parameters (modified method described by Kruijsen et $a l^{25}$ ).
RADIOGRAPHY

The right and left knees of each animal were mounted on cardboard and imaged on high speed $x$-ray film (Kodak) using a Faxitron machine (Field Emission Corporation, Oregon, USA). Blinded assessment of the sections was made by three operators on the basis of (a) evidence of bone demineralisation, (b) degree of destruction, and (c) new bone formation. Tissues were graded from 0 to 3 according to the presence and severity of the above parameters (modified method described by Clark et $a l^{26}$ ).

STATISTICAL ANALYSIS

Results for knee swelling are presented as mean (SEM) and differences between groups compared by Student's $t$ test. Comparisons shown in tables 1 and 2 were made by rank correlation.

\section{Results}

\section{JOINT SWELLING}

Figure 1 compares the results obtained after an i-a injection of PPD in Wistar and Lewis rats. These results relate to the rats sacrificed on day 42 (the end) of the experiment; because animals were killed in the course of the experiment, we aimed, for statistical reasons, to avoid a decreasing number of rats at each time point. Nevertheless, there were no significant differences in the sacrificed groups of animals with respect to the incidence or the magnitude of flares.

Intra-articular injection of PPD in Wistar rats (fig 1A; mean value of four rats) induced acute inflammation with joint swelling, maximal two to three days after injection ( $p<0.01$ and $p<0.05 v$ PBS control) as previously described, ${ }^{19}$ but subsiding later. The same treatment in Lewis rats showed a different pattern (fig $1 \mathrm{~B}$; mean value of six rats): the initial acute response was seen at day 2 ( $\mathrm{p}<0.001 v$ PBS and non-injected controls), subsiding by day 9 , but this was followed by further flares of arthritis with knee swelling at a peak on days $14(\mathrm{p}<0.05 v$ PBS and noninjected controls), 24 ( $\mathrm{p}<0.01 v$ PBS and non-injected controls) and $34(\mathrm{p}<0.05 v$ PBS and non-injected controls). Moreover, the response at day 24 was significantly increased $(p<0.05)$ compared with the day 9 background (end of the acute response) and approached significance $(\mathrm{p}<0.07)$ with respect to day 27 (day of the subsiding flare). Repetition of this experiment with a larger group of rats showed highly significant flares $(p<0.001)$, but these were not synchronous. Although the flares did not reach baseline values, we attribute this to the transient arthritis developed by some animals after $M . t b$ sensitisation (see below).

The two control groups, vehicle (PBS) injected and non-injected, showed no significant swelling.

To assess if the response of Lewis rats to PPD could be attributed to hsp65, a group of 10 M.tb sensitised Lewis rats were injected i-a 

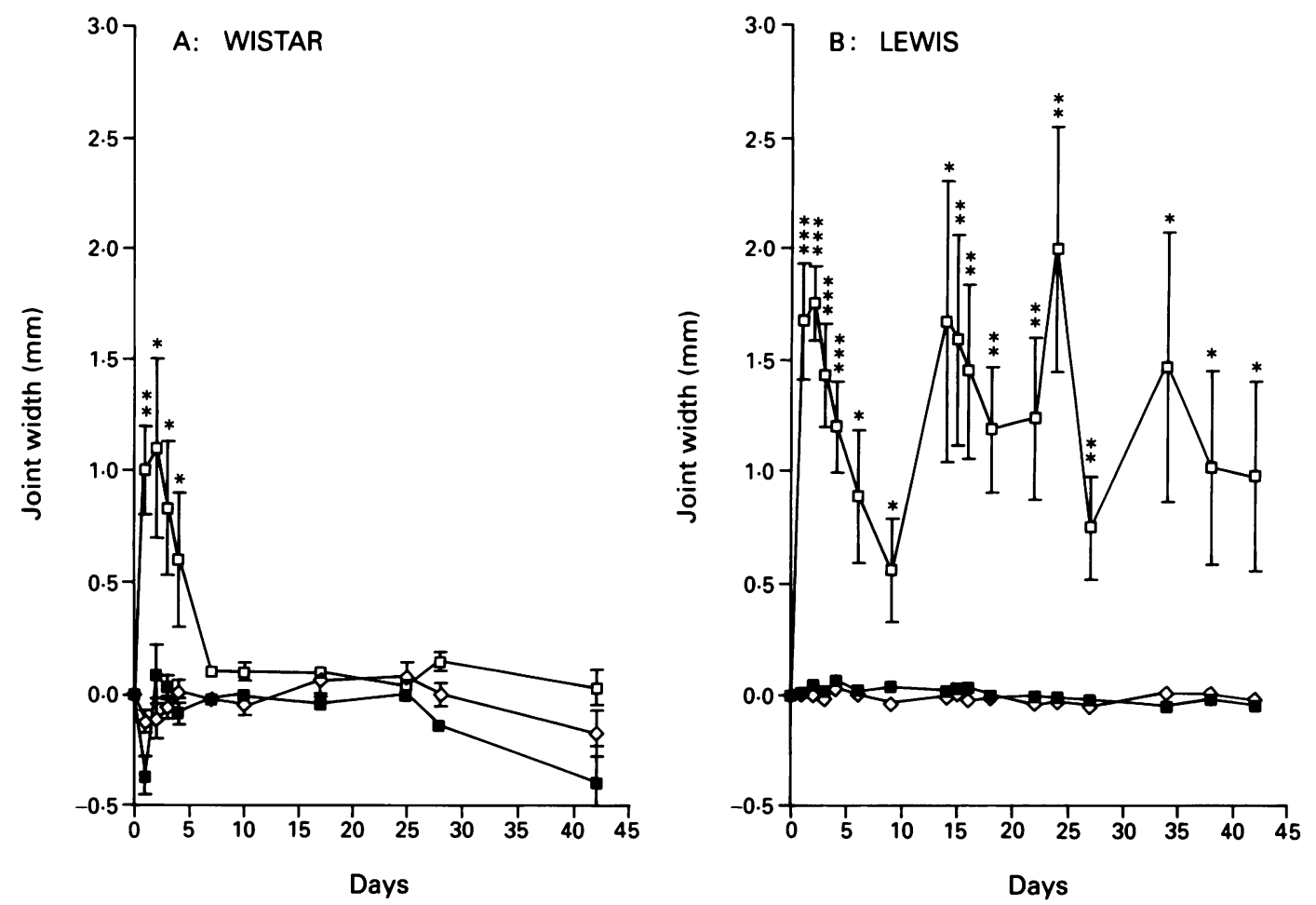

Figure 1 Time course of joint swelling after $i$-a injection of PPD in four Wistar $(A)$ and six Lewis (B) rats pre-sensitised with M.tb in oil and challenged $i$-a with either $50 \mu g$ PPD in PBS ( $\square)$ or PBS alone ( $\square)$, compared with a control group $(\diamond)$ which was not injected. Foint measurements represent mean (SEM) difference in width between injected and non-injected joints. Significant differences compared with PBS: ${ }_{p}<0.05 ;{ }^{\star} p<0.01 ;{ }^{\star \star *} p<0.001$.

with rhsp65 in PBS. All of the rats showed the acute inflammatory peak, but only $50 \%$ of the rats suffered the chronic relapsing profile. As figure 2 shows, the flares reached very high peaks for two rats, while the other three displayed more moderate responses.

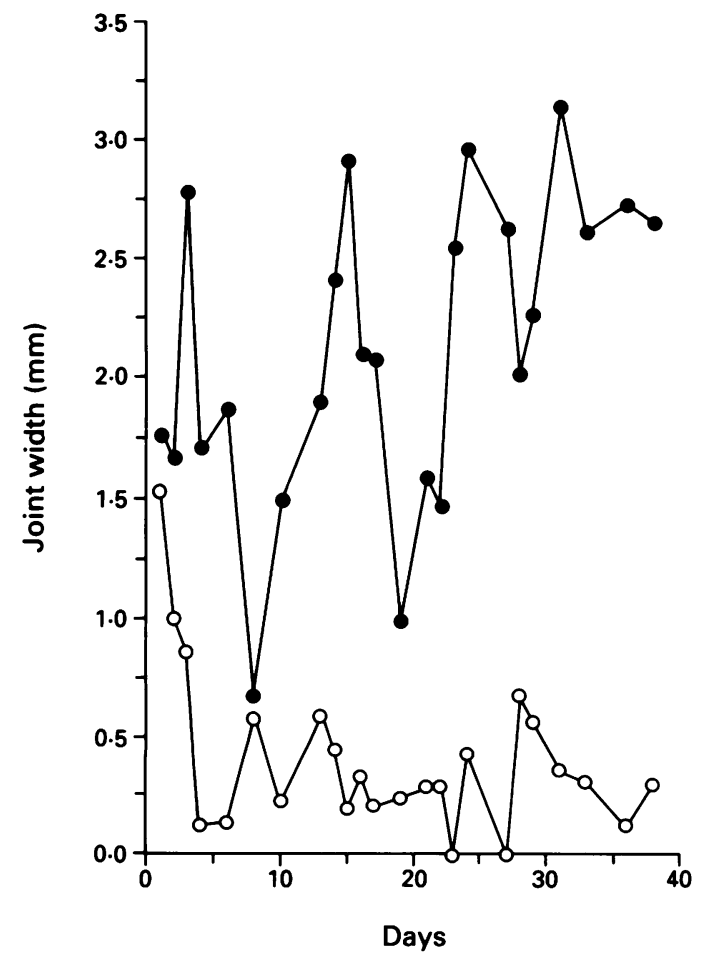

INCIDENCE OF ARTHRITIS AFTER M.tb SENSITISATION

Classically, adjuvant arthritis is induced by a single injection of $M . t b$ in light paraffin oil into the tail. Here, we have sensitised animals using a similar preparation administered in the nape

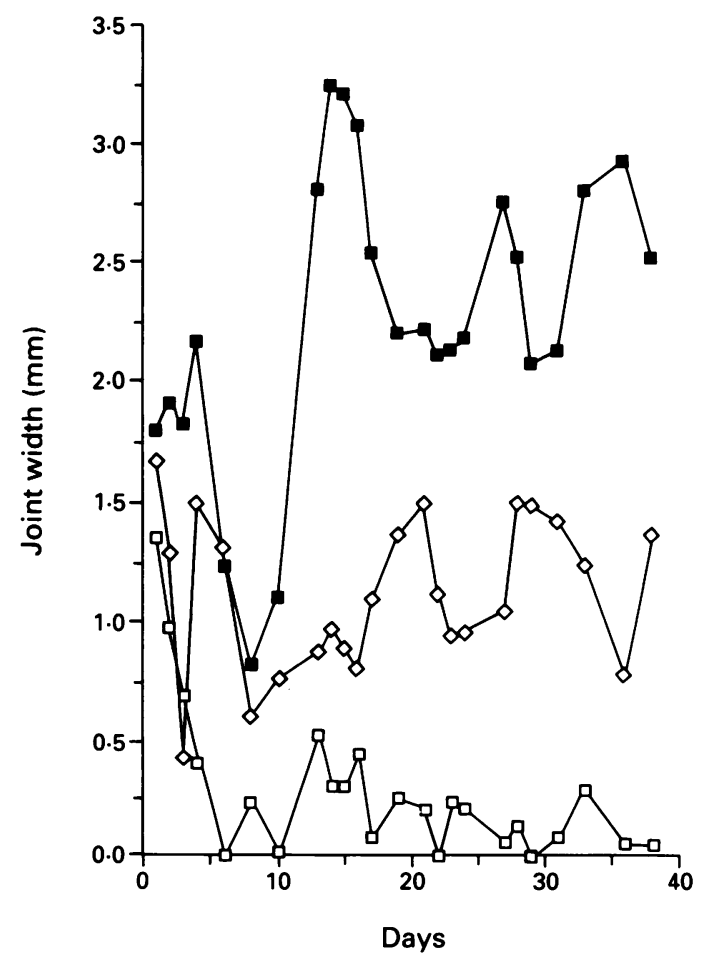

Figure 2 Time course of joint swelling in individual Lewis rats sensitised with $\mathbf{M}$.tb in oil and injected $i$ - $a$ in one knee with rhsp65 $50 \mu \mathrm{g}$ in PBS. Foint measurements represent difference in width between injected and non-injected joints. Each line represents a single rat; each showed a different magnitude of chronic response. $O=$ Rat $1 ; \square=$ rat $2 ; O=$ rat $3 ; \square=$ rat 4 ; $\diamond=$ rat 5 . 
Table 1 Histological scores for the time course of monoarthritis in Wistar $(W)$ rats $(n=4)$ and Lewis $(L)$ rats $(n=6)$. Each parameter was graded from 0 to 3 relative to severity

\begin{tabular}{|c|c|c|c|c|c|}
\hline & Rat strain & Day 3 & Day 14 & Day 28 & Day 42 \\
\hline \multirow[t]{2}{*}{ Joint cavity: fibrin-like material } & $\mathrm{L}$ & $2 \cdot 5(0 \cdot 5)$ & $2 \cdot 0(0 \cdot 6)$ & $0.2(0 \cdot 2)$ & $0 \cdot 0(0 \cdot 0)$ \\
\hline & W & $2.6(0.4)$ & $0.6(0 \cdot 6)$ & $0.2(0 \cdot 2)$ & $0.0(0.0)$ \\
\hline \multirow[t]{2}{*}{ Synovium: cellular infiltration } & $\mathrm{L}$ & $3.0(0.0)$ & $2 \cdot 2(0 \cdot 4)$ & $2 \cdot 0(0 \cdot 3)$ & $2.0(0.4)$ \\
\hline & $\mathrm{W}$ & $2 \cdot 6(0 \cdot 2)$ & $1.4(0.4)$ & $0.6(0.4)$ & $0.0(0 \cdot 0)$ \\
\hline \multirow[t]{2}{*}{ AC: destruction at pannus junction } & $\mathrm{L}$ & $2 \cdot 3(0.5)$ & $2 \cdot 0(0.6)$ & $2 \cdot 4(0 \cdot 2)$ & $1.5(0.5)$ \\
\hline & W & $2 \cdot 0(0 \cdot 6)$ & $0.8(0.6)$ & $0 \cdot 4(0 \cdot 4)$ & $0.0(0.0)$ \\
\hline \multirow[t]{2}{*}{ Periostitis } & $\mathrm{L}$ & $2.3(0.5)$ & $0.6(0 \cdot 4)$ & $0 \cdot 8(0 \cdot 2)$ & $0.0(0.0)$ \\
\hline & $\mathrm{W}$ & $0.8(0.6)$ & $1 \cdot 0(0 \cdot 3)$ & $1 \cdot 0(0 \cdot 3)$ & $0.0(0.0)$ \\
\hline
\end{tabular}

Values are mean $(\mathrm{SEM}) . \mathrm{AC}=$ articular cartilage.

of the neck. Despite this non-optimal route of administration for induction of adjuvant arthritis, the animals developed a mild and transient arthritis confined to the hind limbs; only $40 \%$ of the rats were slightly arthritic between day 14 and day 22 after M.tb sensitisation (usually the days of the clinical onset in classic adjuvant arthritis). Therefore, the underlying mild arthritis in some animals may contribute to the larger standard errors observed in some groups and thus the increase in baseline values. It appears that PPD injected animals suffer a low grade arthritis with superimposed acute flares.

HISTOPATHOLOGY AND RADIOGRAPHY

At day 3, in both strains of rats, i-a administration of PPD induced an acute inflammatory response with oedema, cellular infiltration, and deposition of fibrin-like material in the joint.

Tables 1 and 2 show histological and radiological scores for both groups. The joint cavity was enlarged as a result of inflammatory effusion and deposition of fibrin-like material, trapping large numbers of polymophonuclear cells (PMN) sometimes showing a cellular organisation. The synovium completely lost its normal structure of an intima one to two cells deep lying on adipose tissue. The synovial lining cells were hypertrophic and the intimal cell layer hyperplastic. The subsynovium was infiltrated by large numbers of inflammatory cells (PMN and macrophages). At day 3, an erosive front (pannus) was already evident: it appeared to originate symmetrically on both sides of the bone heads, eroding articular cartilage and subchondral bone (fig $3 \mathrm{C}$ and $\mathrm{E}$ ). Radiologically, the joints showed normal features (fig 4C and E).

From day 14 onwards a histological difference between the two strains was apparent. While Lewis rats developed a chronic phase, Wistar rats recovered from the acute phase. On days 28 and 42 (fig $3 F$ ), joint sections from

Table 2 Radiographic scores of the time course experiments on Wistar $(W)$ rats $(n=4)$ and Lewis $(L)$ rats $(n=6)$. Each parameter was graded from 0 to 3 relative to severity. The maximum possible score for each animal was 12

\begin{tabular}{lllll}
\hline Rat strain & Day 3 & Day 14 & Day 28 & Day 42 \\
\hline Lewis & $1.0(0.0)$ & $3.4(1.2)$ & $8.0(1 \cdot 2)^{\star}$ & $8.0(1.9)^{\star \star}$ \\
Wistar & $0.0(0.0)$ & $1.4(1.4)$ & $0.0(0.0)$ & $0.0(0 \cdot 0)$ \\
\hline
\end{tabular}

Values are mean (SEM)

${ }^{\star} \mathrm{p}<0.05,{ }^{\star \star} \mathrm{p}<0.01 v$ Wistar rats. four of five Lewis rats showed displacement of haemopoietic tissue from the epiphysis and its replacement with osteoblastic tissue. Randomly orientated trabecula of new woven bone were present and in some cases disrupted the epiphysial growth plate. Ectatic and congested vessels were seen within the epiphysis and there was a varying degree of disruption of endochondral ossification in the metaphysis. Marginal, erosive pannus was seen overlying articular cartilage and in some cases, peripheral new bone formation was apparent. There was, however, no evidence of periarticular calcification and also no evidence of bone or fat necrosis and no vessel thrombosis, ruling out avascular necrosis. Radiologically, these changes appear to correlate with remodelling of the femoral condyle with patchy areas of lucency and sclerosis (fig 4F).

In contrast, on days 28 and 42 (figs 3D and 4D), Wistar rats showed only minor changes. Marginal pannus was seen in some cases, but the epiphysial bone changes were not apparent. The contralateral joints of all (Wistar and Lewis) PPD injected groups showed minimal cellular infiltration; both knee joints of PBS injected (figs 3A, B, 4A, B) and noninjected animals were normal.

\section{Discussion}

We have demonstrated previously that rhsp65 or PPD injected i-a in M.tb sensitised Wistar rats induced swelling and acute inflammation implying a recruitment of arthritogenic $\mathrm{T}$ cells; $\alpha \beta$ positive $T$ cells were detected at day 3 by immunohistology. ${ }^{19}$ We suggested that these $T$ cells may be capable of inducing arthritis and recognising both mycobacterial hsp65 and a self-antigen of joint cartilage. ${ }^{5}{ }^{6}$ Here, we have shown that $\mathrm{i}$-a tuberculin PPD and rhsp65 in primed animals can induce a chronic, persistent synovitis with pannus formation, cartilage destruction and bone erosion.

It is perhaps not surprising that PPD, which contains hsp65 (a strong immunoreactive component of $M . t b)$ causes inflammation in $M . t b$ sensitised rats. What are interesting, however, are the recurrent flares in Lewis rats. The predominant feature of RA is the chronic relapsing articular inflammation and it has been postulated that a possible mechanism is the sudden release of antigen. The majority of animal models of arthritis tend to be self-limiting and are characterised by an acute and a chronic phase with a spontaneous remission. ${ }^{2021}$ In antigen-induced mono- 

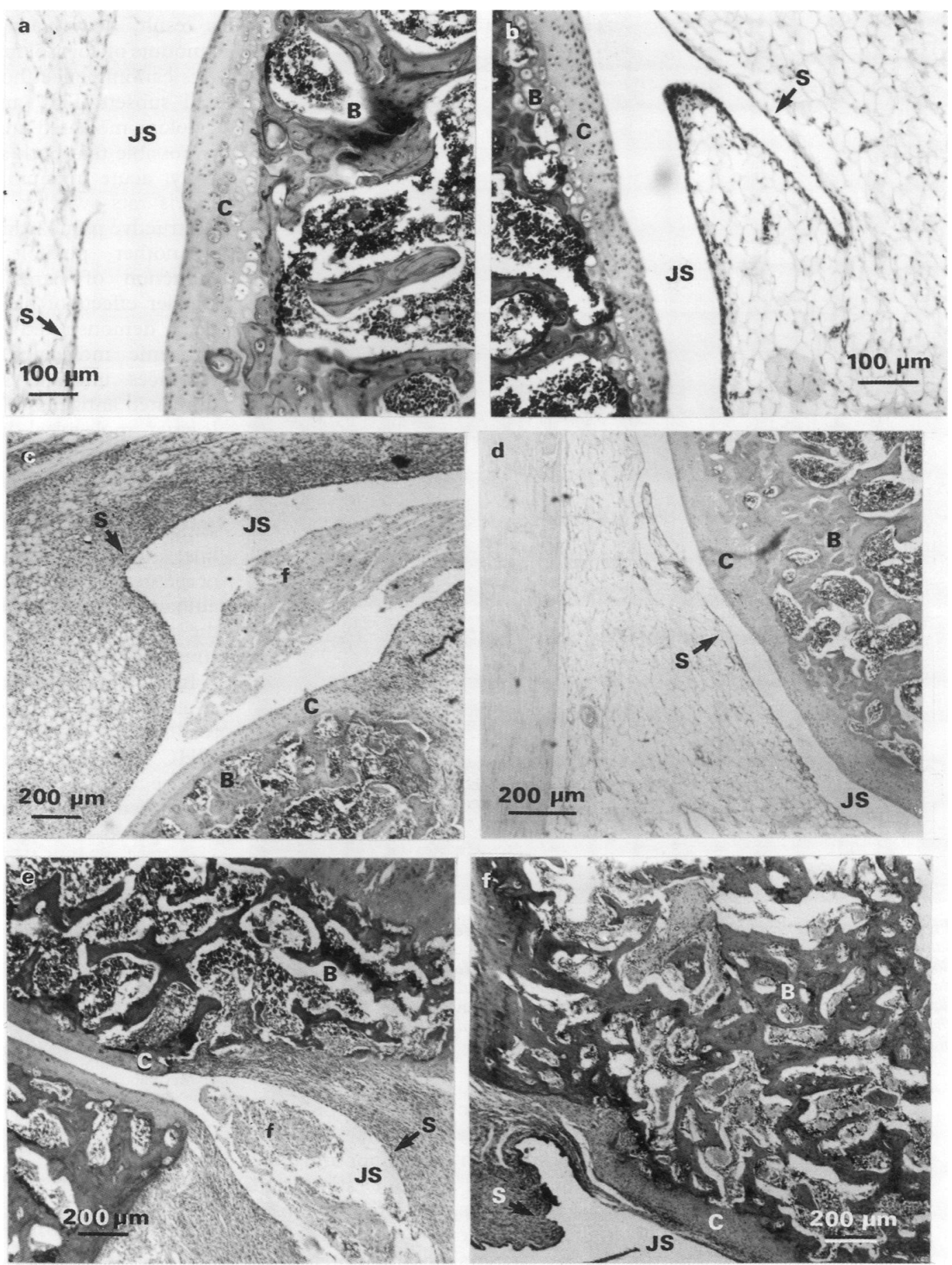

Figure 3 Histology of acute (day 3) and chronic responses (day 42) in knee joints of rats. For each day of sacrifice a group of four to six rats were killed; midline sagittal sections from knee joints were cut and stained with haematoxylin and eosin. Control group (Wistar and Lewis, PBS-injected): day 3(a) and day 42(b) show a normal thin synovial layer and cartilage. Wistar rats (PPD-injected): day 3(c) shows a massive inflammatory cell infiltration of the synovium with fibrin and entrapped leucocytes deposited in the joint space; day $42(d)$ shows complete resolution of the inflammatory response. Lewis rats (PPD-injected): day 3(e) shows the same inflammatory features described for Wistar; day 42(f) shows a chronic reaction involving synovitis and pannus formation with erosion of the edge of the cartilage surface. $\mathcal{F}=$ foint space; $S=$ synovium; $B=$ bone; $C=$ cartilage; $f$ fibrin-like material.

arthritis, the disease is reactivated only by rechallenge with antigen, either orally ${ }^{27}$ or intravenously. ${ }^{28}$ Here, the Lewis rats showed spontaneous flares without rechallenge with antigen. We hypothesise that these secondary flares may be induced in primed animals by 'self' hsp released from the synovium, and will discuss possible reasons for the different pattern of response of these two strains of rats.

Bacterial cell wall-induced arthritis causes a chronic disease lasting 10 months. The poor biodegradability of the bacterial polymers accounts for the chronicity, while the slow release from hepatic stores of bacterial products, originating from the intestinal lumen, accounts for the flares. ${ }^{29}$ In our experiment, retained antigen may sustain the persistent inflammation but the recurrent flares might be caused by sudden upregulation and presentation of endogenous hsp65; this view is supported by the demonstration that acute inflammation, induced in the mouse foot pad with incomplete Freund's adjuvant (that is, in the absence of exogenous bacterial hsp65), can 

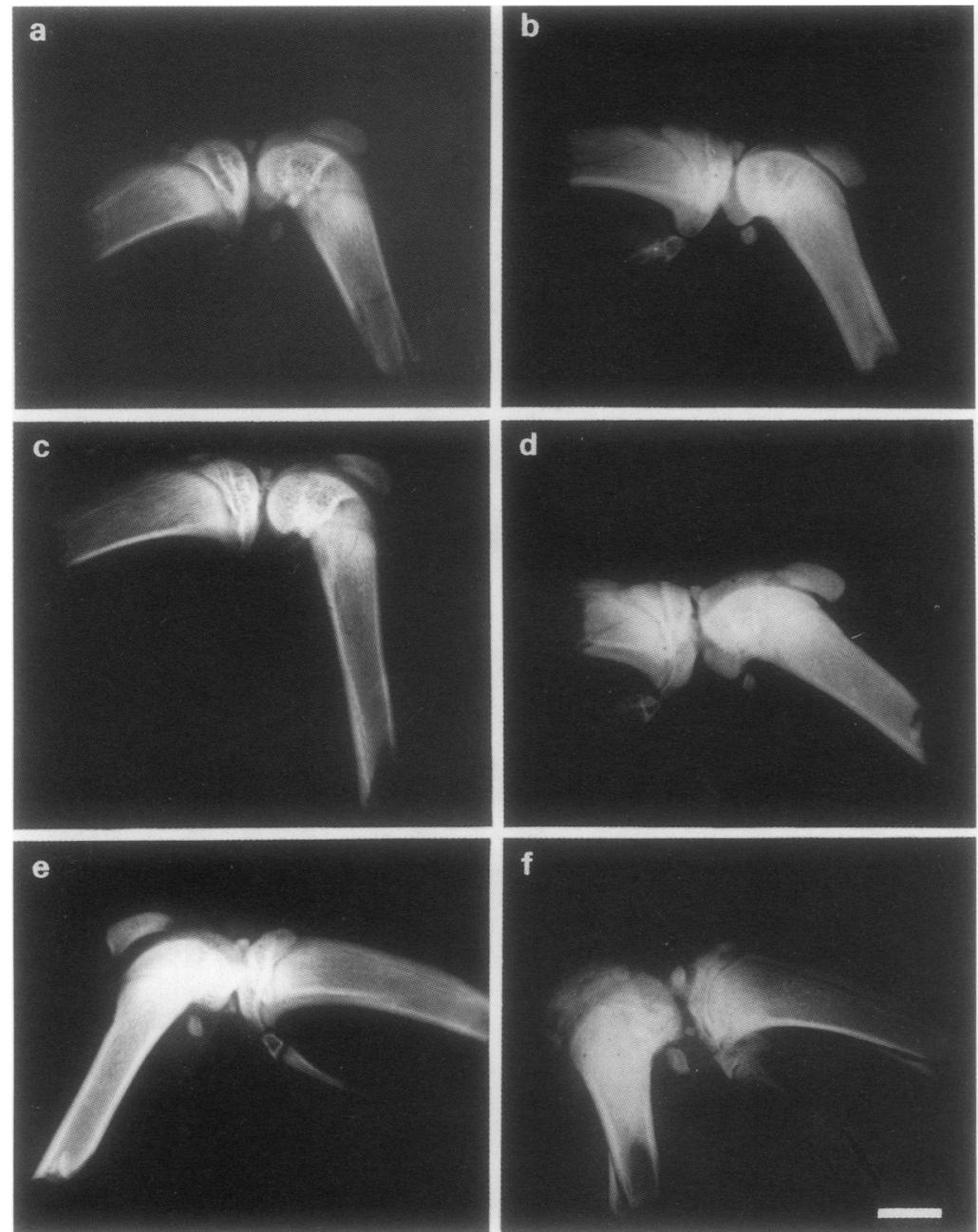

Figure 4 Radiography of acute (day 3) and chronic responses (day 42) in knee joints of the same animals represented in figure 3. Control group (Wistar and Lewis PBS-injected): day 3 (a) and day 42(b) indicate a normal compact joint. Wistar rats (PPD-injected): day $3(c)$, despite acute inflammation, shows a joint with normal features; day 42(d) still illustrates a healthy knee joint. Lewis rats (PPD-injected): day 3(e), like Wistar (c), shows a normal joint; day 42(f) shows remodelling of the femoral condyle with patchy areas of lucency and sclerosis and peripheral new bone formation.

activate $T$ cells specific for self hsp65 but cross reactive with mycobacterial hsp65. 30 Alternatively, it is known that minor antigenic (cryptic) determinants are not stimulated under normal conditions, but such responses may be induced by a cross reactive major determinant on a bacterial or viral protein. ${ }^{31}$ In the inflamed synovium, the first wave of reactive $T$ cells to hsp could induce loss of tolerance to cryptic (auto)antigens, resulting in a cascade of autoimmune responses. These responses are major histocompatibility complex haplotype dependent-providing one possible explanation for the different patterns we observed in Lewis and Wistar rats. Therefore, in arthritic patients, the presence of hsp65, which we have shown to be upregulated in the arthritic synovium, ${ }^{13}$ may account for the amplification and perpetuation of inflammatory synovitis and the associated increase in the cellular and humoral immune response to hsp65. 113233 Moreover, we know that inbred Lewis rats are predisposed to develop arthritis not only because of their genetic background but also via a defect in the cytokinehypothalamo-pituitary-adrenal axis ${ }^{2} 2$-a condition also reported in patients with RA. ${ }^{23}$ As a result, Lewis rats fail to secrete adequate amounts of cortisol from the adrenal gland and this can influence the balance of the $\mathrm{T}$ helper cell subsets $\mathrm{TH} 1$ and $\mathrm{TH} 2$ which regulate cytokine mediated immune responses; ${ }^{34}$ thus it is possible that both strains of rats develop an early, acute inflammatory response which in Lewis rats switches to a chronic, relapsing, destructive monoarthritis.

Another possible explanation for the induction of flares might be the known 'carrier effect' of heat shock proteins. It has been demonstrated that the use of highly antigenic molecules such as PPD greatly enhances immune responses to associated unrelated antigens. ${ }^{35}$ This same effect of using 'carrier molecules' has been achieved with recombinant mycobacterial hsp. ${ }^{36}$ Recently it has been shown that hsp65 provides greatly enhanced recognition of tumour-associated antigen in a malignant macrophage tumour cell line. ${ }^{37}$ Thus joint inflammation could be perpetuated by an enhanced recognition of an autoantigen such as collagen or proteoglycan in the presence of increased concentrations of stress proteins.

In conclusion, our findings show a differential response to i-a presentation of hsp65 in two strains of rat. Lewis rats, having both MHC and neuroendocrine defects, show a disease course that is relapsing, as in RA. Wistar rats, an outbred strain, not genetically predisposed to develop arthritis and with no neuroendocrine disorders, show a spontaneously remissive pathology, possibly akin to a transient reactive arthritis. ${ }^{3} 38$

We thank the Arthritis and Rheumatism Council for Research for financial support (VRW and PIM; Grant No B0141) and Italfarmaco $\mathrm{SpA}$ for sponsorship of $\mathrm{SR}$. We are most grateful to $S$ Kerslake for technical assistance.

1 Phillips P E. Infectious agents in the pathogenesis of rheumatoid arthritis. Semin Arthritis Rheum 1986; 16: 1-10.

2 McCulloch J, Lydyard P M, Rook G A W. Rheumatoid arthritis: how well do the theories fit the evidence? Clin Exp Immunol 1993; 92: 1-6.

3 Gaston J S H, Life P F, Granfors K, et al. Synovial $T$ lymphocyte recognition of organisms that trigger reactive arthritis. Clin Exp Immunol 1989; 76: 348-53.

4 Rook G A W, Lydyard P M, Stanford J L. A reappraisal of the evidence that rheumatoid arthritis and several other idiopathic diseases are slow bacterial infections. Ann Rheum Dis 1993; 52: S30-8.

5 Cohen I R, Holoshitz J, van Eden W, Frenkel A $\mathrm{T}$ lymphocyte clones illuminate pathogenesis and affect therapy of experimental arthritis. Arthritis Rheum 1985; 28: 841-5.

6 van Eden W, Thole J E R, van der Zee R, et al. Cloning of the mycobacterial epitope recognised by $T$ lymphocytes in adjuvant arthritis. Nature 1988; 331: 171-3.

7 Yang X D, Gasser J, Feige U. Prevention of adjuvant arthritis in rats by a nonapeptide from the $65-\mathrm{kD}$ mycobacterial heat shock protein: specificity and mechanism. Clin Exp Immunol 1992; 87: 99-104.

8 Billingham M E J, Carney S, Butler R, Colston M J. A mycobacterial $65-\mathrm{kD}$ heat shock protein induces antigen-specific suppression of adjuvant arthritis, but is not itself arthritogenic. $\mathcal{F}$ Exp Med 1990; 171: 339-44

9 van den Broek M F, Hogervorst E J M, van Bruggen M C J, van Eden W, van der Zee R, van den Berg W B. Protection against streptococcal cell wall-induced arthritis by pretreatment with the $65-\mathrm{kD}$ mycobacterial heat shock protein. F Exp Med 1989; 170: 449-66.

10 Thompson S J, Rook G A W, Brealey R J, van der Zee R, Elson C J. Autoimmune reactions to heat-shock proteins in pristane-induced arthritis. Eur f Immunol 1990; 20: in pristan $2479-84$.

11 Res P C M, Schaar C G, Breedveld F C, et al. Synovial fluid mycobacteria in early chronic arthritis. Lancet 1988; ii: mycobacter

12 Gaston J S H, Life P F, Bailey L C, Bacon P A. In vitro responses to a 65 -kilodalton mycobacterial protein by synovial $T$ cells from inflammatory arthritis patients. fImmunol 1989; 143: 2494-500. 
13 Winrow V R, Mojdehi G, Mapp P I, Rampton D S, Blake D R. Immunohistological localisation of stress proteins in inflammatory tissue. In: Burdon $\mathrm{R}$, Rice-Evans C, Blake D, Winrow V, eds. Stress proteins in inflammation. London: Richelieu Press, 1990: 237-51.

14 de Graeff-Meeder E R, Voorhorst M, van Eden W, et al. Antibodies to the mycobacterial $65-\mathrm{kD}$ heat-shock Antibodies to the mycobacterial $65-\mathrm{kD}$ heat-shock
protein are reactive with synovial tissue of adjuvant protein are reactive with synovial tissue of adjuvant arthritic rats and patients with rheumatoid ar
osteoarthritis. Am $\mathcal{F}$ Pathol 1990; 137: 1013-7.

15 Del Giudice G, Gervaix A, Costantino P, et al. Priming to heat shock proteins in infants vaccinated against pertussis. f Immunol 1993; 150: 2025-32.

16 Symmons D P M, Chakravarty K. Can immunisation trigger rheumatoid arthritis? Ann Rheum Dis 1993; 52: $843-4$

17 Oldstone M B A. Molecular mimicry and autoimmune disease. Cell 1987; 50: 819-20.

18 Thole J E R, Dauwerse H G, Das P K, Groothuis D G, Schouls L M, van Embden J D A. Cloning of Mycobacterium bovis BCG DNA and expression of antigens in Escherichia coli. Infect Immun 1985; 50: antigens

19 Winrow V R, Ragno S, Morris C J, et al. Arthritogenic potential of the $65 \mathrm{kDa}$ stress protein-an experimental potential of the $65 \mathrm{kDa}$ stress protein-an

20 Klareskog L. What can we learn about rheumatoid arthritis from animal models? Springer Semin Immunopathol 1989; 11: $315-33$.

21 Billingham M E J. Models of arthritis and the search for anti-rheumatic drugs. In: Orme M, ed. Anti-rheumatic drugs. New York: Pergamon Press, 1990: 1-47.

22 Sternberg E M, Hill J M, Chrousos G P, et al. Inflammatory mediator-induced hypothalamic-pituitary-adrenal axis activation is defective in streptococcal cell wall arthritissusceptible Lewis rats. Proc Natl Acad Sci USA 1989; 86: susceptible

23 Chikanza C, Petrou P, Kingsley G, Chrousos G, Panayi G S. Defective hypothalamic response to immune and inflammatory stimuli in patients with rheumatoid arthritis. Arthritis Rheum 1992; 35: 1281-8.

24 Lamb F I, Kingston A E, Estrada G I, Colston M J. Heterologous expression of the 65-kilodalton antigen of Mycobacterium leprae and murine T-cell responses to the gene product. Infect Immun 1988; 56: 1237-41.

25 Kruijsen M W M, van den Berg W B, van de Putte L B A Sequential alterations of periarticular structures in antigeninduced arthritis in mice. Histological observatic fibrous capsule, ligaments, bone and muscles, using whole joint sections. Br $\mathfrak{F}$ Exp Path 1983; 64: 298-305.

26 Clark R L, Cuttino J T, Anderle S K, Cromartie W J, Schwab J H. Radiologic analysis of arthritis in rats after systemic injection of streptococcal cell wall. Arthritis Rheum 1979; 22: 25-35.

27 Lens J W, van den Berg W B, van de Putte L B A, van den Bersselaar L. Flare-up of antigen-induced arthritis in mice 58: $364-71$.

28 van de Putte L B A, Lens J W, van den Berg W B, Kruijsen $M$ W $M$. Exacerbation of antigen-induced arthritis after challenge with intravenous antigen. Immunology 1983; 49: 161-7.

29 Lichtman S N, Bachmann S, Munoz S R, et al. Bacterial cell wall polymers (peptidoglycan-polysaccharide) cause reactivation of arthritis. Infect Immun 1993; 61: 4645-53.

30 Anderton S M, van der Zee R, Goodacre J A. Inflammation activates self hsp60-specific T cells. Eur f Immunol 1993; 23: 33-8.

31 Gammon G, Sercarz E. How some T cells escape tolerance induction. Nature 1989; 342: 183-5.

32 Gaston J S H, Life P F, Jenner P J, Colston M J, Bacon P A. Recognition of a mycobacteria-specific Bacon $\mathrm{P}$ A. Recognition of a mycobacteria-specific epitope in the 65-kD heat-shock protein by synovial

33 Tsoulfa G, Rook G A W, Bahr G M, et al. Elevated IgG antibody levels to the mycobacterial $65-\mathrm{kDa}$ heat shock protein are characteristic of patients with rheumatoid arthritis. Scand f Immunol 1989; 30: 519-27.

34 Daynes R A, Araneo B A. Contrasting effects of glucocorticoids on the capacity of $T$ cells to produce the growth factors interleukin-2 and interleukin-4. Eur $\mathcal{f}$ Immunol 1989; 19: 2319-25.

35 Vyakarnam A, Lachmann P J, Sia D Y. The killing of tumour cell targets coupled to tuberculin (PPD) by human and murine PPD-reactive T helper clones. I PPD specificity of killing. Scand F Immunol 1988; 27: 337-46.

36 Lussow A R, Barrios C, van Embden J, et al. Mycobacterial heat-shock proteins as carrier molecules. Eur $\mathcal{f}$ Immunol 1991; 21: 2297-302.

37 Lukacs K V, Lowrie D B, Stokes R W, Colston M J. Tumour cells transfected with a bacterial heat-shock gene lose tumorigenicity and induce protection against tumors. f Exp Med 1993; 178: 343-8.

38 Sieper J, Braun J, Wu P, Kingsley G. T cells are responsible for the enhanced synovial cellular immune response to triggering antigen in reactive arthritis. Clin Exp Immunol 1993; 91: 96-102. 